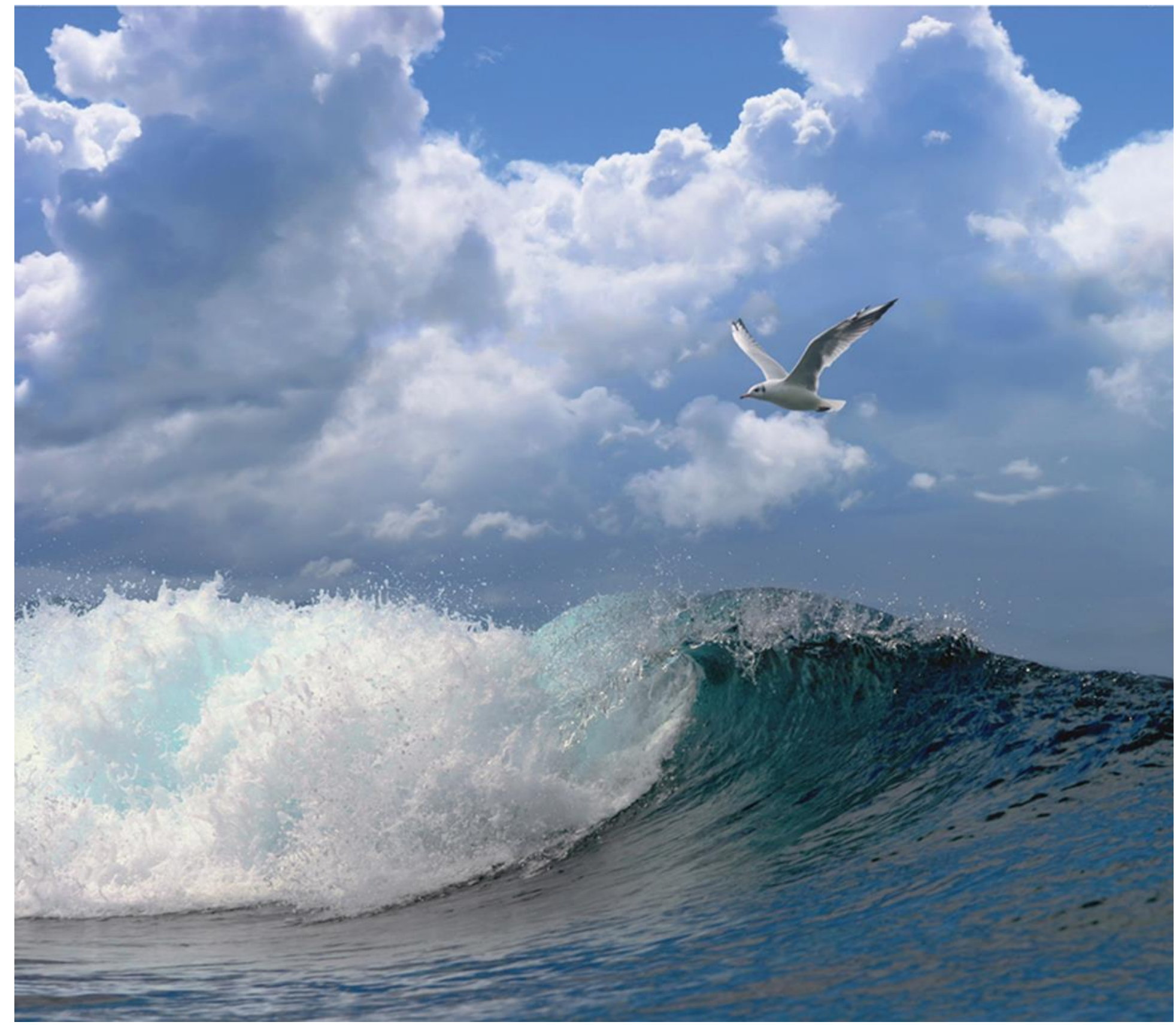

\title{
Plastic in Noordzeevis in relatie tot het verlies van MSC Zoe containers begin 2019
}




\section{Plastic in Noordzeevis in relatie tot het verlies van MSC Zoe containers begin 2019}

Auteurs: Susanne Kühn, André Meijboom, Maarten van Hoppe, Jan Andries van Franeker 
Keywords: MSC Zoe, microplastic, vis

Opdrachtgever: Rijkswaterstaat Noord-Nederland

T.a.v.: Afdeling Netwerkontwikkeling en Visie

Postbus 2232

3500 GE Utrecht

Dit rapport is gratis te downloaden van https://doi.org/10.18174/532654

Wageningen Marine Research verstrekt geen gedrukte exemplaren van rapporten.

Wageningen Marine Research is ISO 9001:2015 gecertificeerd.

(c) Wageningen Marine Research

Wageningen Marine Research, instituut binnen de rechtspersoon Stichting

Wageningen Research, hierbij vertegenwoordigd door Dr. M.C.Th. Scholten, Algemeen directeur

KvK nr. 09098104,

WMR BTW nr. NL 8113.83.696.B16.

Code BIC/SWIFT address: RABONL2U

IBAN code: NL 73 RABO 0373599285
Wageningen Marine Research aanvaardt geen aansprakelijkheid voor gevolgschade, noch voor schade welke voortvloeit uit toepassingen van de resultaten van werkzaamheden of andere gegevens verkregen van Wageningen Marine Research. Opdrachtgever vrijwaart Wageningen Marine Research van aanspraken van derden in verband met deze toepassing.

Alle rechten voorbehouden. Niets uit deze uitgave mag weergegeven en/of gepubliceerd worden, gefotokopieerd of op enige andere manier gebruikt worden zonder schriftelijke toestemming van de uitgever of auteur. 


\section{Inhoud}

$1 \quad$ Introductie

2 Methodes $\quad 6$

3 Resultaten $\quad 7$

$\begin{array}{lll}3.1 & \text { IBTS vissen } & 7\end{array}$

$\begin{array}{llr}3.2 & \text { Discard vissen } & 8\end{array}$

$\begin{array}{ll}3.3 & \text { Aangespoelde scharren op Ameland } \\ \end{array}$

4 Conclusies $r$

$5 \quad$ Kwaliteitsborging $\quad 12$

$\begin{array}{lr}\text { Literatuur } & 13\end{array}$

$\begin{array}{lr}\text { Verantwoording } & 14\end{array}$ 


\section{Samenvatting}

Tijdens een storm verloor het vrachtschip ZOE vele containers dicht bij de Nederlandse en Duitse kust. Een deel van de verloren lading bestond uit verschillende plastic korrels. In maaginhouden van diverse Noordzeevissen werd gekeken of deze specifieke plastics teruggevonden konden worden. Hiervoor werden 1087 vissen uit de Noordzee onderzocht, die in 2019 gevangen werden. Er werden kleine hoeveelheden plastics waargenomen, de hoeveelheid is vergelijkbaar met aantallen plastics die voor het Zoe incident gevonden zijn. Geen van de gevonden plastic stukjes lijkt op de door Zoe verloren materialen. 


\section{$1 \quad$ Introductie}

Begin januari 2019 verloor het vrachtschip MSC Zoe tijdens een storm ca. 350 containers. De volledige inhoud van deze containers blijft onbekend, maar er zijn substantiële hoeveelheden industriële plastic pellets (High Density PolyEthyleen HDPE) in $25 \mathrm{~kg}$ zakken en ca. 11 ton EPS (Expanded PolyStyrene) granulaat bestemd voor de productie van polystyreen piepschuim in zee terecht gekomen (Figuur 1). Verdere details over materiaal eigenschappen worden in de integrale rapportage over de ecologische consequenties van het incident met de MSC Zoe behandeld die in januari 2021 door WMR en NIOZ zal worden opgeleverd. Dit deel-rapport richt zich op plastics in de magen van vissen uit de Noordzee.
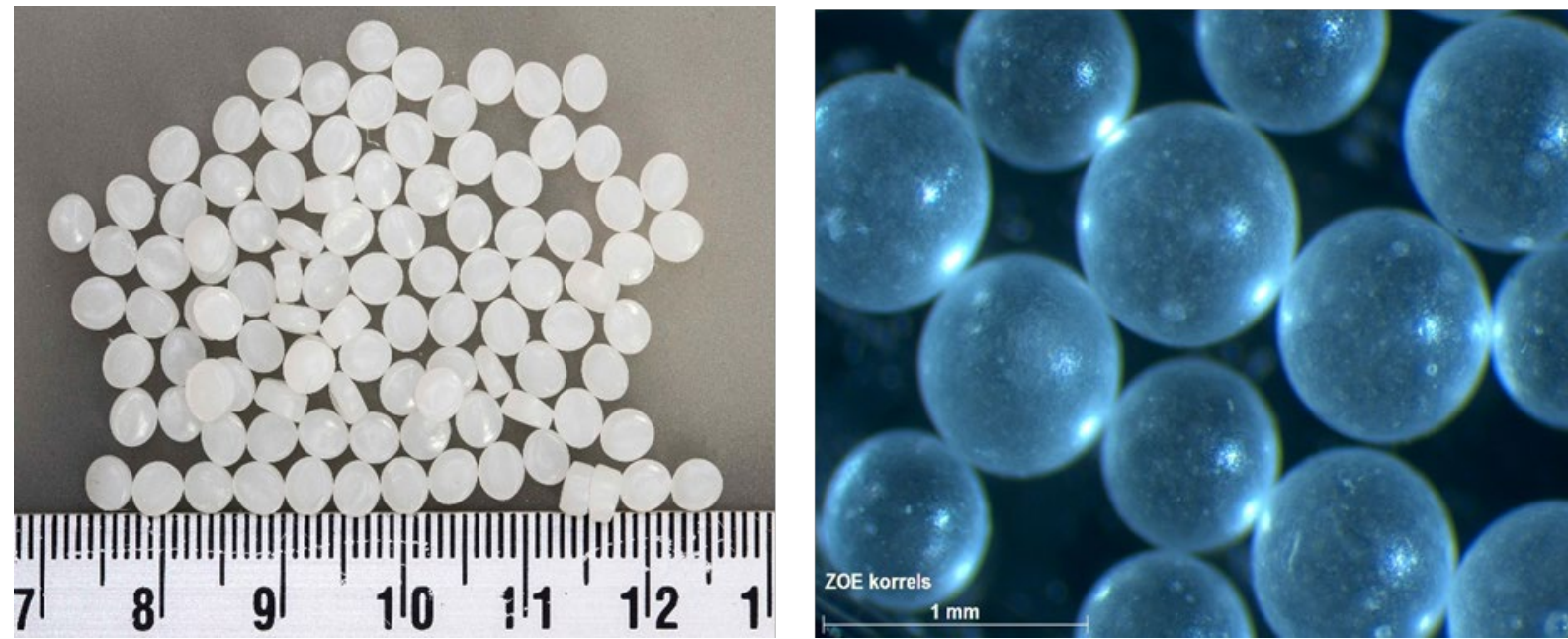

Figuur 1. Industriële HDPE pellets en EPS microbeads (sterk uitvergroot) afkomstig van de MSC Zoe lading.

Vissen in de Noordzee zijn al vaker onderzocht op de aanwezigheid van plastics in hun maag-darmstelsel (Foekema et al. 2013; Lusher et al. 2013; Rummel et al. 2016; Kühn et al. 2020). De mogelijkheid om vissen binnen de EU als monitoringsoort voor plastic in de waterkolom en op de zeebodem te gebruiken wordt regelmatig bediscussieerd (Galgani et al. 2013; Bray et al. 2019; Kühn et al. 2020). Voor dit deelproject van het Zoe onderzoek werd gekeken naar plastics in het maag-darmsysteem van verschillende Noordzee-vissoorten. 


\section{Methodes}

Voor dit deelproject werden 1078 vissen uit twee standaard onderzoeksprogramma's gebruikt:

- 224 vissen zijn tijdens de International Bottom Trawl Survey (IBTS) in januari en februari 2019 gevangen. Deze vissen komen van negen stations nabij het gebied waar Zoe containers overboord waren gegaan (Figuur 2). Deze vissen werden individueel op plastic onderzocht.

- 854 vissen van diverse stations uit de Nederlandse Discard Survey die speciaal voor het Zoe onderzoek zijn bewaard. Deze vissen zijn of kort na het overboord slaan van de Zoe containers, of door het jaar 2019 heen in de buurt van het incident verzameld (Figuur 3). Vanwege het grote aantal beschikbare vissen, werden deze gegroepeerd (in batches) onderzocht.

Op 4 Januari 2019, dus zeer kort na het container incident, werden bij Paal 15.5 op Ameland, 9 dood aangespoelde scharren (Limanda limanda) verzameld door Theo Kiewiet tijdens een strand survey naar dode vogels. Vanwege het tijdstip als ook locatie in relatie tot het Zoe incident werden deze vissen in dit onderzoek meegenomen en individueel geanalyseerd.

Alle vissen werden ontleed en het maag-darmstelsel werd opgelost in kaliumhydroxide ( $\mathrm{KOH}$, concentratie: 1 Molair). $\mathrm{KOH}$ lost veel natuurlijk weefsel op, maar plastics blijven intact (Kühn et al., 2017). Daardoor wordt de analyse van de monsters eenvoudiger en efficiënter. Na het oplossen van weefsel werden alle maaginhouden boven een $0.3 \mathrm{~mm}$ zeef gespoeld. Met deze zeefmaat kunnen ook de kleine door MSC ZOE verloren EPS korrels met een diameter van $\pm 0.7 \mathrm{~mm}$ gevonden worden. De $0.3 \mathrm{~mm}$ zeefmaat is ook als kleinste maat bij het ZOE onderzoek naar plastic in zeevogels gebruikt (zie Zoe deelproject rapport over zeevogels: van Franeker \& Kühn, 2020), zodat resultaten goed vergelijkbaar zijn. 


\section{Resultaten}

De resultaten worden per survey/vangstmethode besproken.

\subsection{IBTS vissen}

In totaal werden er 224 vissen van 5 soorten onderzocht (Tabel 1). Sprot en haring zijn pelagische vissoorten, terwijl wijting, kabeljauw en schol dicht bij de bodem leven. In drie van de 124 onderzochte haringen uit de IBTS vissen werd plastic gevonden. Eén haring bevatte een blauw plastic draadje en twee andere hadden ieder een microbead ingeslikt (Figuur 2). Deze doorzichtige microbeads zijn in grootte vergelijkbaar met de door MSC Zoe verloren EPS korrels maar waren helder en bevatten relatief grote 'gasbellen' (Figuur 2), terwijl de 'Zoe korrels' een licht witte, melkige kleur hebben en geen grote gasbellen bevatten (Figuur 1). In de 100 individuen samengesteld uit de andere vissoorten werd geen plastic aangetroffen. Van alle IBTS vissen had dus gemiddeld $1.3 \%$ plastic in het maagdarmstelsel.

Tabel 1. Soort en aantal vissen die voor het Zoe IBTS onderzoek geanalyseerd werden, samen met het aantal plastics en de frequentie van voorkomen (\%FO) die per soort gevonden zijn.

\begin{tabular}{|c|c|c|c|c|c|c|}
\hline Soort & Wetenschappelijke naam & Vangstdatum & $\mathrm{n}$ vis & n plastics & \%FO & Opmerking \\
\hline Haring & Clupea harengus & Jan + Feb 2019 & 124 & 3 & 2 & $\begin{array}{l}2 x \text { microbead; } 1 x \\
\text { draadje }\end{array}$ \\
\hline Wijting & Merlangius merlangus & Jan + Feb 2019 & 47 & 0 & 0 & \\
\hline Sprot & Sprattus sprattus & Feb 2019 & 27 & 0 & 0 & \\
\hline Schol & Pleuronectes platessa & Jan 2019 & 23 & 0 & 0 & \\
\hline Kabeljauw & Gadus morhua & Jan 2019 & 3 & 0 & $(0)$ & \\
\hline Totaal & & & 224 & 3 & 1.3 & $\begin{array}{c}0.01 \text { plastics } \\
\text { per vis }\end{array}$ \\
\hline
\end{tabular}




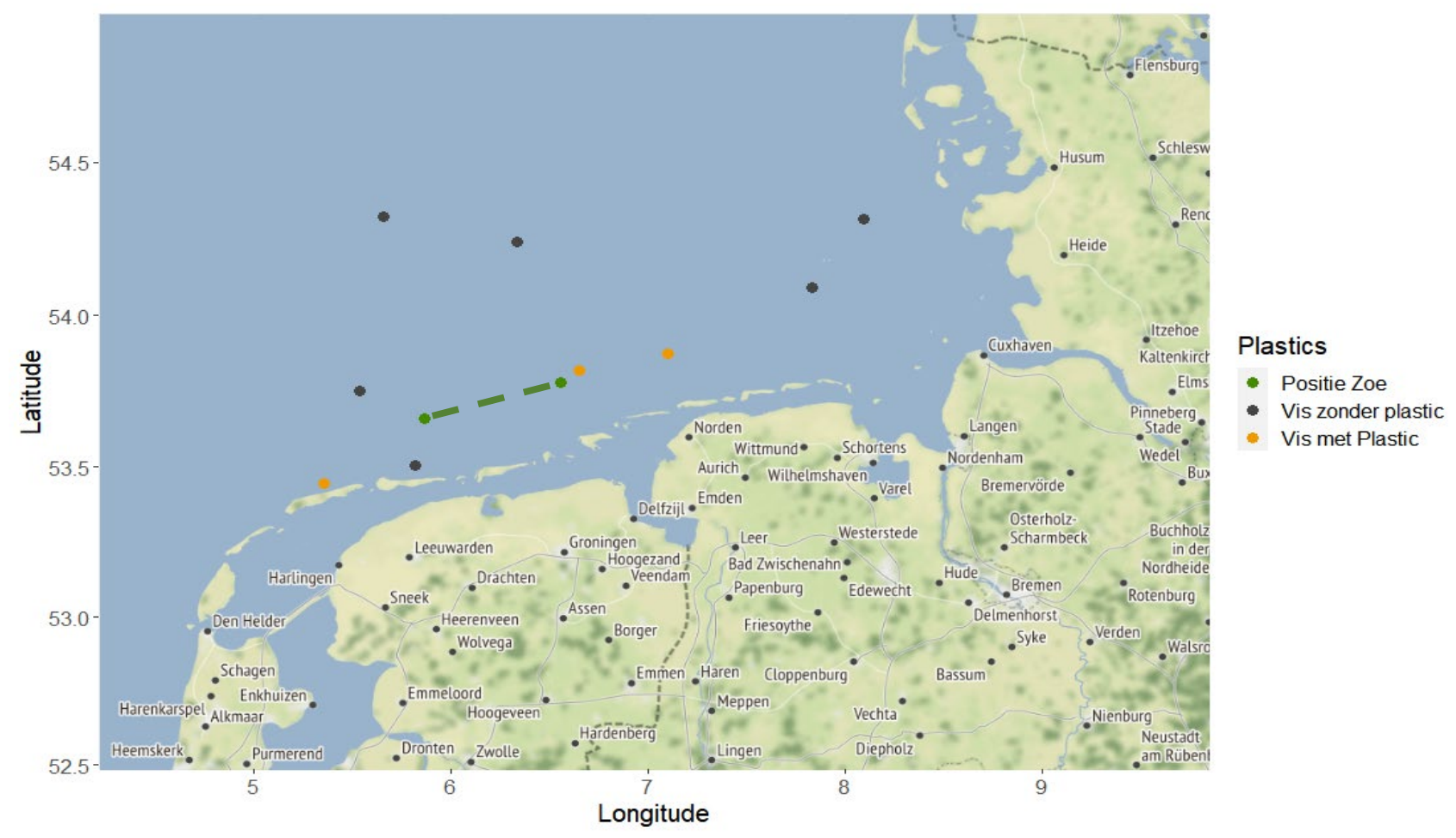

Figuur 2. Kaart van de locaties waar IBTS vissen voor dit onderzoek gebruikt werden. De twee groene cirkels met stippellijn tonen de begin- en eindlocatie, waartussen de meeste containers van de MSC Zoe overboord gevallen zijn. De oranje cirkels tonen de drie locaties waar plastic in vis gevonden werd. De grijze cirkels verwijzen naar stations, waar geen plastic in vis werd aangetroffen.
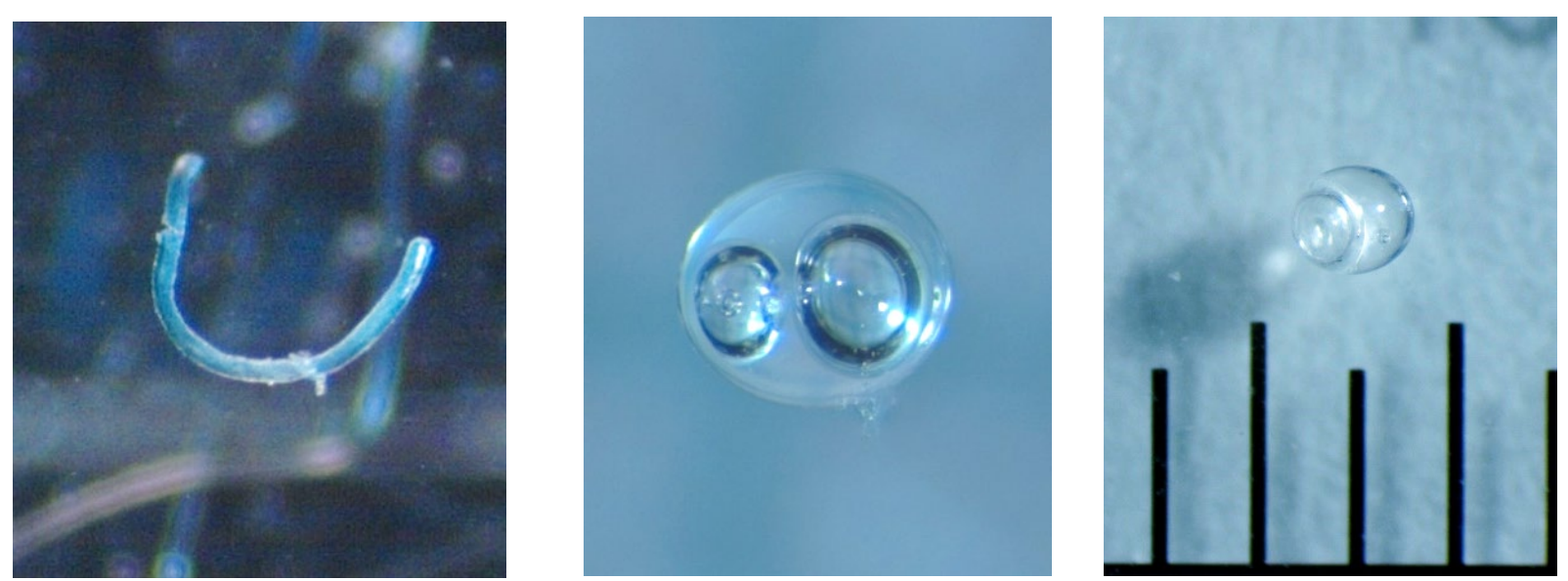

Figuur 3. Links: een plasticdraad gevonden in een haring in februari. Midden en Rechts: microbeads gevonden in twee andere haringen die in januari gevangen werden.

\subsection{Discard vissen}

Alle onderzochte Discard vissoorten zijn afkomstig uit de boomkor visserij en leven en foerageren dicht bij de zeebodem. In de meeste onderzochte soorten werd geen plastic aangetroffen. Dit betreft vooral soorten met een laag aantal onderzochte vissen ( $<100$ vissen). Eén van 213 schollen had een blauw velletje van $1 \times 0.5 \mathrm{~mm}$ ingeslikt. Bij schar werd in twee batches plastic aangetroffen. Eén bevatte twee plastic velletjes, transparant $(2 \times 1 \mathrm{~mm})$ en zwart $(1.2 \times 0.7 \mathrm{~mm})$ van kleur. Een andere batch van 50 scharren bevatte een opmerkelijk aantal van 25 plastic microbeads. De vissen waren gevangen op 18 
Juli 2019 ongeveer $150 \mathrm{~km}$ noordwestelijk van de locatie waar MSC Zoe haar containers kwijt raakte. Deze microbeads waren $0.5 \mathrm{~mm}$ in doorsnee en transparant, vaak met een duidelijk zichtbare ingesloten gasbubbel en leken optisch op de korrels die tijdens de IBTS surveys gevonden werden. Ze lijken daarmee ook niet op de EPS korrels uit Zoe containers. Het is onduidelijk of een enkele vis alle microbeads in één keer in heeft geslikt of dat meerdere vissen uit deze batch de microbeads in hun maag hadden. Los daarvan wijst het hoge aantal microbeads in een enkele vangst erop, dat lokaal grote hoeveelheden microbeads kunnen ophopen en door vis opgegeten worden. In totaal werden in de 854 vissen uit de Discard surveys, 28 microplastics gevonden. Omdat de vis in batches werd geanalyseerd kan een exact percentage van voorkomen niet worden berekend. Maar, bij een aanname dat geen enkele vis meer dan 1 stukje plastic in de maag had, wijst dit op een maximale frequentie van voorkomen (\%FO) van $3.3 \%$.

Tabel 2. Soort en aantal vissen die voor het Zoe Discard onderzoek geanalyseerd werden, samen met het aantal plastics die per soort gevonden zijn.

\begin{tabular}{llccc} 
Soortnaam & Wetenschappelijke naam & $n$ vis & n plastics & Opmerking \\
\hline Schar & Limanda limanda & 269 & 27 & 2 batches, waarvan één met 2 \\
vellen en één met 25 microbeads
\end{tabular}

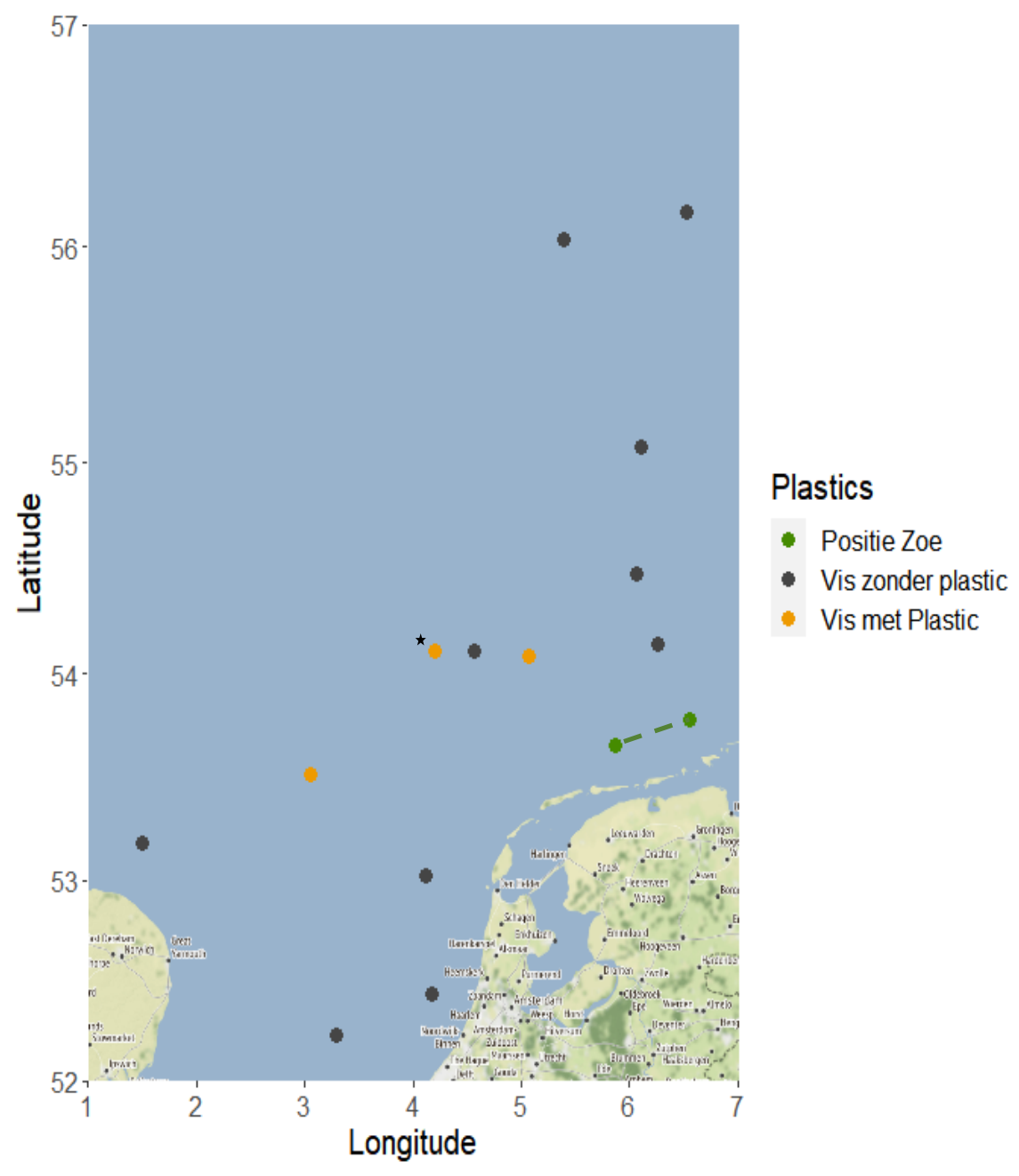

Figuur 4. Kaart van de locaties waar Discard vissen voor dit onderzoek gebruikt werden. De groene cirkels tonen de begin en eind-locatie waar de meeste containers van de MSC Zoe overboord gevallen zijn. De oranje cirkels tonen de drie locaties waar plastic in vis werd gevonden. De locatie gemarkeerd met een $*$ is de plek waar de scharren met 25 korrels gevonden werden. Grijze cirkels zijn locaties waar geen plastic gevonden is. 

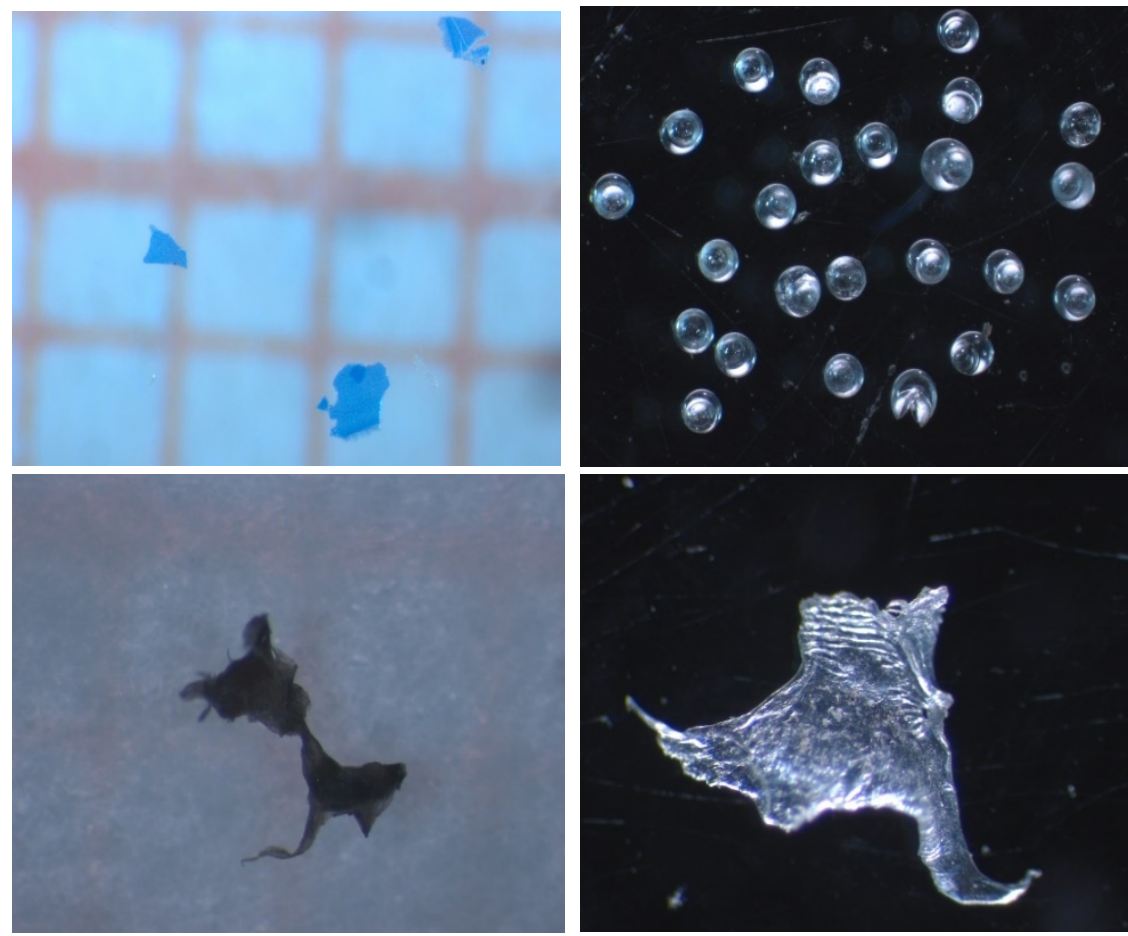

Figuur 5.

Boven links: blauw plastic vel (gebroken tijdens

verwerking), gevonden in een batch van 17 schollen.

Boven rechts: 24

microbeads (1 microbead verloren tijdens

verwerking), gevonden in een batch van 50 schar.

Onder links en rechts: twee plastic velletjes gevonden in een batch van 13 scharren.

\subsection{Aangespoelde scharren op Ameland}

De negen onderzochte scharren die kort na het incident op Ameland aanspoelden, waren gemiddeld $17.6 \mathrm{~cm}$ lang (range 14.5-19.5 cm). De reden, waarom de vissen aanspoelden kon tijdens de dissectie niet achterhaald worden. Er werd geen ingeslikt plastic aangetroffen. 


\section{Conclusies}

In totaal konden voor dit deelproject de maag-darmsysteem van 1087 vissen van tien soorten uit de Noordzee geanalyseerd worden. In de onderzochte vissen werd weinig plastic aangetroffen. Geen van de gevonden plastics kan met zekerheid gerelateerd worden aan de bekende plastics uit de Zoe containers. De resultaten uit dit onderzoek verschillen niet substantieel met de gegevens uit eerder onderzoek van Wageningen Marine Research in de Noordzee: daarbij werd in 4389 vissen van verschillende soorten Noordzeevis, gevangen in de periode 2009 tot 2018 , in $1.8 \%$ van de individuen plastic in het maag-darmsysteem aangetroffen (Kühn et al. 2020). Daarmee kan geen verhoging van plastic in vis door het Zoe incident aangetoond worden. Door het lage voorkomen van plastic in vis, moeten grote hoeveelheden vis onderzocht worden om tot een betrouwbaar resultaat te komen. De vissen met plastics in het huidige onderzoek foerageren zowel in de waterkolom (haring) als ook op de zeebodem (schol en schar). De aanwezigheid van microbeads in haring en schar wijst erop dat dergelijke korrels op verschillende plekken in de waterkolom terecht kunnen komen. Terwijl de scharren de korrels ca. $150 \mathrm{~km}$ ten noorden van de Zoe ingeslikt hadden, werden de twee haringen met vergelijkbare korrels op een andere locatie, ten oosten van de Zoe, aangetroffen.

De vergelijkbare grootte en vorm van de in vis gevonden korrels wijst erop, dat kleine plastic korrels, zoals die bij het Zoe incident overboord zijn geslagen, door vis kunnen worden ingeslikt. 


\section{$5 \quad$ Kwaliteitsborging}

Wageningen Marine Research beschikt over een ISO 9001:2015 gecertificeerd kwaliteitsmanagementsysteem. Dit certificaat is geldig tot 15 december 2021. De organisatie is gecertificeerd sinds 27 februari 2001. De certificering is uitgevoerd door DNV GL. 


\section{Literatuur}

Bray L, Digka N, Tsangaris C, Camedda A, Gambaiani D, de Lucia GA, Matiddi M, Miaud C, Palazzo L, Pérez-del-Olmo A, Raga JA, Silvestri C, Kaberi H (2019) Determining suitable fish to monitor plastic ingestion trends in the Mediterranean Sea. Environmental Pollution 247: 1071-1077 doi https://doi.org/10.1016/j.envpol.2019.01.100

Foekema EM, De Gruijter C, Mergia MT, van Franeker JA, Murk AJ, Koelmans AA (2013) Plastic in North Sea Fish. Environmental Science \& Technology 47: 8818-8824 doi https://doi.org/10.1021/es400931b

Galgani F, Hanke G, Werner S, Oosterbaan L, Nilsson P, Fleet D (2013) Monitoring guidance for marine litter in European Seas, JRC Scientific and Policy reports, pp 120

Kühn S, van Werven B, van Oyen A, Meijboom A, Bravo Rebolledo EL, van Franeker JA (2017) The use of potassium hydroxide $(\mathrm{KOH})$ solution as a suitable approach to isolate plastics ingested by marine organisms. Marine Pollution Bulletin 115: 86-90 doi http://dx.doi.org/10.1016/j.marpolbul.2016.11.034

Kühn S, van Franeker JA, O'Donoghue AM, Swiers A, Starkenburg M, van Werven B, Foekema E, Hermsen E, Egelkraut-Holtus M, Lindeboom H (2020) Details of plastic ingestion and fibre contamination in North Sea fishes. Environmental Pollution 257: 113569 doi https://doi.org/10.1016/j.envpol.2019.113569

Lusher A, McHugh M, Thompson R (2013) Occurrence of microplastics in the gastrointestinal tract of pelagic and demersal fish from the English Channel. Marine Pollution Bulletin 67: 94-99 doi http://dx.doi.org/10.1016/j.marpolbul.2012.11.028

Rummel CD, Löder MG, Fricke NF, Lang T, Griebeler E-M, Janke M, Gerdts G (2016) Plastic ingestion by pelagic and demersal fish from the North Sea and Baltic Sea. Marine Pollution Bulletin 102: 134-141 doi https://doi.org/10.1016/j.marpolbul.2015.11.043

van Franeker JA, Kühn S (2020) Onderzoek naar plastic in magen van noordse stormvogels en andere zeevogels in relatie tot het verlies van MSC-ZOE containers in begin januari 2019. Wageningen Marine Research, Den Helder, The Netherlands, pp 19 doi https://doi.org/10.18174/531132 


\section{Verantwoording}

Rapport C087/20

Projectnummer: 4315100134

Dit rapport is met grote zorgvuldigheid tot stand gekomen. De wetenschappelijke kwaliteit is intern getoetst door een collega-onderzoeker en het verantwoordelijk lid van het managementteam van Wageningen Marine Research

Akkoord:

Dr. E.M. Foekema

Senior onderzoeker

Handtekening:

Datum:

15 oktober 2020

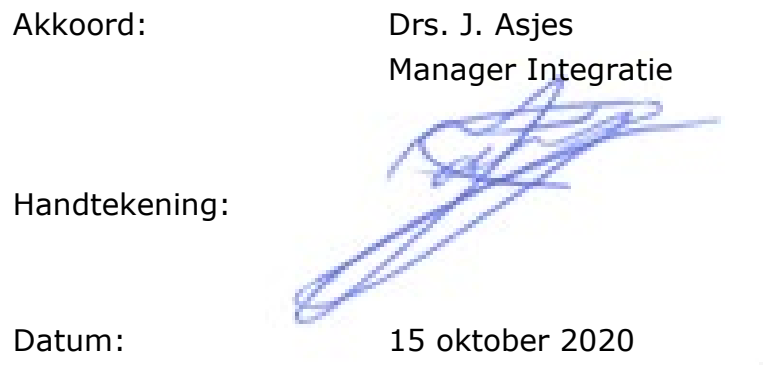


Wageningen Marine Research

T: $+31(0) 317480900$

E: marine-research@wur.nl

www.wur.nl/marine-research

Bezoekers adres:

- Ankerpark 271781 AG Den Helder

- Korringaweg 7, 4401 NT Yerseke

- Haringkade 1, 1976 CP IJmuiden
Wageningen Marine Research levert met kennis, onafhankelijk wetenschappelijk onderzoek en advies een wezenlijke bijdrage aan een duurzamer, zorgvuldiger beheer, gebruik en bescherming van de natuurlijke rijkdommen in zee-, kust- en zoetwatergebieden.
Wageningen Marine Research is onderdeel van Wageningen University \& Research. Wageningen University \& Research is het samenwerkingsverband tussen Wageningen University en Stichting Wageningen Research en heeft als missie: 'To explore the potential of nature to improve the quality of life' 